\title{
Long-acting beta-agonists plus inhaled corticosteroids safety: a systematic review and meta-analysis of non-randomized studies
}

\author{
Gimena Hernández ${ }^{1,2}$, Mónica Avila1,3, Àngels Pont 1,3 , Olatz Garin 1,3 , Jordi Alonso 1,3,4, Laurent Laforest ${ }^{5}$,
} Christopher J Cates ${ }^{6}$, Montserrat Ferrer ${ }^{1,2,3^{*}}$ and ASTRO-LAB group

\begin{abstract}
Background: Although several systematic reviews investigated the safety of long-acting beta-agonists (LABAs) in asthma, they mainly addressed randomized clinical trials while evidence from non-randomized studies has been mostly neglected. We aim to assess the risk of serious adverse events in adults and children with asthma treated with LABAs and Inhaled Corticosteroids (ICs), compared to patients treated only with ICs, from published non-randomized studies.

Methods: The protocol registration number was CRD42012003387 (http://www.crd.york.ac.uk/Prospero). Literature search for articles published since 1990 was performed in MEDLINE and EMBASE. Two authors selected studies independently for inclusion and extracted the data. A third reviewer resolved discrepancies. To assess the risk of serious adverse events, meta-analyses were performed calculating odds ratio summary estimators using random effect models when heterogeneity was found, and fixed effect models otherwise.

Results: Of 4,415 candidate articles, 1,759 abstracts were reviewed and 220 articles were fully read. Finally, 19 studies met the inclusion criteria. Most of them were retrospective observational cohorts. Sample sizes varied from 50 to 514,216 . The meta-analyses performed (69,939-624,303 participants according to the outcome considered) showed that odds ratio of the LABAs and ICs combined treatment when compared with ICs alone was: 0.88 (95\% Cl 0.69-1.12) for asthma-related hospitalization; 0.75 (95\% Cl 0.66-0.84) for asthma-related emergency visits; 1.02 (95\% Cl 0.94-1.10) for systemic corticosteroids; and 0.95 (95\% Cl 0.9-1.0) for the combined outcome.

Conclusions: Evidence from observational studies shows that the combined treatment of LABAs and ICS is not associated with a higher risk of serious adverse events, compared to ICs alone. Major gaps identified were prospective design, paediatric population and inclusion of mortality as a primary outcome.
\end{abstract}

Keywords: Asthma, Long-acting beta-agonists, Inhaled corticosteroids, LABAs, Serious adverse events, Exacerbations

\section{Background}

Long-Acting Beta-Agonists (LABAs) -salmeterol and formoterol- were introduced in the ' 90 s when they demonstrated reducing symptoms and use of rescue medication [1]. Concerns about their safety appeared in 1993 when Castle et al. reported a threefold mortality in a randomized clinical trial (RCT) comparing LABAs with

\footnotetext{
* Correspondence: mferrer@imim.es

${ }^{1}$ Health Services Research Group. IMIM (Hospital del Mar Medical Research Institute), Barcelona Biomedical Research Park, office 144. Doctor Aiguader, 88 | 08003, Barcelona, Spain

${ }^{2}$ Universitat Autònoma de Barcelona, Bellaterra, Spain

Full list of author information is available at the end of the article
}

SABAs [2]. Post-marketing reports of adverse events showed an increased risk of death and serious asthma events [3]. The Salmeterol Multicenter Asthma Research Trial was stopped in 2003 after an interim analysis showed a fourfold increased mortality amongst patients randomized to salmeterol vs. placebo [4]. Similar concerns about formoterol were raised by a reanalysis of three RCTs. Meta-analyses of RCTs with LABAs as a monotherapy indicated an increased mortality risk $[5,6]$.

Meta-analyses of RCTs examining the safety of LABAs in combination with inhaled corticosteroids (ICs) showed inconsistent results. Most of them found no significant 
differences in asthma-related hospitalizations and asthmarelated mortality compared with patients treated with ICs alone [7-11]. But a statistically significant increase of catastrophic asthma events for LABAs plus ICs was shown by the update of a meta-analysis [12]. In 2010, the Federal Drug Administration (FDA) required label changes to indicate contraindication of use of LABAs without concomitant ICs, recommending only fixed-dose LABAs plus ICs combination, and calling for new studies to address this issue [13].

Nevertheless, there is still a lack of knowledge regarding LABAs' safety with concomitant ICs use, with both theoretical arguments and limited empirical evidence that ICs may mitigate LABA-associated risks [14-16]. Most of the systematic reviews currently available are based on RCTs, which may present limitations to assess long-term and rare outcomes [5,8-11]. Moreover, RCTs may not reflect the actual patterns of use of these medications in asthma patients' day-to-day regarding treatment duration and adherence. To our knowledge, there is only one systematic review of observational studies [17]. Its meta-analysis showed that the combined treatment was associated with a lower risk of asthma-related hospitalizations and/or emergency room visits.

Since year 2008, end date of the above mentioned review, many non-randomized studies have been published, especially due to the FDA's 2010 call for further evidence. The aim of this study was to assess the risk of serious adverse events in patients with asthma treated with LABAs and ICs in comparison to patients treated only with ICs, by synthesizing the available evidence from non-randomized studies through systematic review and meta-analysis.

\section{Methods}

The protocol registration number was CRD42012003387 (http://www.crd.york.ac.uk/Prospero). We searched MEDLINE and EMBASE databases with a specific strategy (see Additional file 1) from 1990, when LABAs were commercialized, to January $20^{\text {th }}, 2013$.

We looked for non-randomized studies in all languages (non-randomized controlled trials, controlled before-after studies, prospective or retrospective cohorts, case-control studies) on adults, adolescents or children with asthma diagnosis. Studies assessing treatment with LABAs plus ICs (either as two separate inhalers or as a single inhaler) compared with ICs monotherapy were considered, regardless of the dose (see Additional file 1). Co-therapy such as immunomodulators and leukotriene modifiers were not excluded. We defined 'severe exacerbation' following the American Thoracic Society/European Respiratory Society statement [18] which was based on urgent health care utilization: asthma-related emergency department (ED) visits, hospitalizations, intubations, intensive care unit (ICU) admissions, and use of systemic corticosteroids were considered either specific or combined outcomes.

Two members of the study team, a physician $(\mathrm{GH})$ and a pharmacist (MA), independently reviewed studies found in the literature search by examining titles, abstracts, and full text articles. A third reviewer (MF) resolved discrepancies. A pilot test was performed to homogenize criteria among reviewers. Finally, the selected articles' reference lists were reviewed to identify other possible studies that could be included.

Data were extracted by agreement of two reviewers using a standardized, predefined data collection form, including: study and participants characteristics, interventions, comparator, outcomes, asthma severity, comedication, and ethics consideration of each study. Authors were contacted if clarification was needed.

The risk of bias in the identified studies was assessed using a checklist developed by members of the Cochrane Non-Randomised Studies Methods group [19]. We assessed 4 categories of potential biases: groups of comparison, reasons for allocation in groups, parts of the study that were prospective, and group comparability (Additional file 1).

\section{Analytic strategy}

Reported adjusted OR and 95\% confidence intervals (95\% CI) for the comparison of ICs plus LABAs versus ICs alone were considered. Where adjusted ORs were not reported, unadjusted ORs were held. To assess the risk of severe exacerbation in patients with asthma treated with LABAs plus ICs, compared to those treated only with ICs, meta-analyses were carried out for individual specific adverse events and combined outcomes. Subgroup analyses for children and administration mode were planned. The summary OR and 95\% CI estimated in the meta-analyses, together with ORs from individual studies, were presented in forest plots.

Heterogeneity among studies was evaluated using Galbraith plot and $\mathrm{I}^{2}$ statistic categorized as follows: $<30 \%$ not important; 30\%-50\% moderate; 50\%-75\% substantial; and $75 \%-100 \%$ considerable [19]. If significant heterogeneity was identified among studies, further examination of the individual studies was conducted, and random effects models (Dersimonian-Laird Method) were used to obtain the summary OR estimates. Otherwise, fixed effects models were used (Mantel-Haentzel Method). Publication bias was assessed by Egger regression asymmetry test and funnel plots. The meta-analytic software program used was STATA.12.

\section{Results}

\section{Literature search results}

The literature search identified 4,415 articles (Figure 1). After excluding 195 duplicates, 4,220 titles and 1,759 


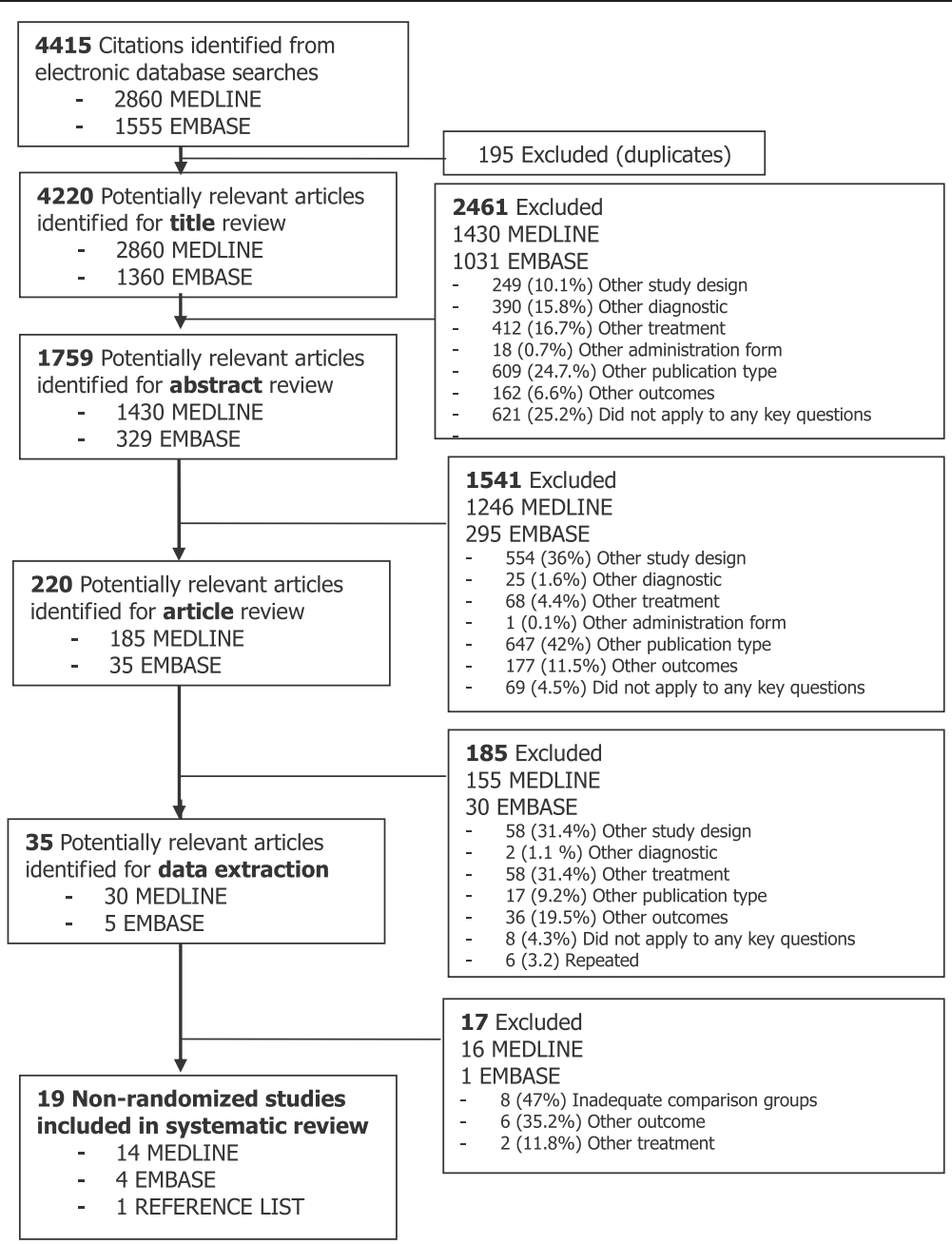

Figure 1 Flow chart diagram.

abstracts were reviewed, reading fully 220 articles. The most frequent reason for exclusion during title and abstract review was "did not apply to any key question" (25.2\%), and "other publication type" (42\%), respectively; and during full text review, presenting "other study designs" (31.4\%) or evaluating "other treatments" (31.4\%). Detailed reasons for excluding manuscripts at each step are displayed in Additional file 1. Seventeen of the potentially relevant articles were excluded after full text reading (characteristics are shown in Additional file 1). Finally, 19 studies met the inclusion criteria.

\section{Characteristics of included studies}

Main characteristics of included studies are displayed in Table 1 . The majority (16/19) were retrospective observational cohorts based on pharmacy claims from insurance databases. These studies analysed patients with asthma who had initiated an inhaled treatment with LABAs plus ICs or ICs alone. There was also 1 prospective observational cohort, 1 case-control study and 1 before-after study. All the articles described studies carried out in either USA (16/19) or UK (3/19). Regarding sample size, number of participants varied from 50 (Nguyen WT et al. 2005) [20] to 514,216 (Guo JJ et al. 2011) [21]. All articles included have been approved by their Ethics Committee

\section{Assessment of risk of bias in individual studies}

An overview of the risk of bias in individual studies is shown in Figure 2. First, all studies compared the LABAs plus ICs group with the ICs alone group, as this was an inclusion criterion. Therefore, risk of bias in this item was not identified. Second, risk related to allocation was intermediate since patients were allocated by treatment decisions and not by location differences, participant's preferences, or based on outcomes. Third, we considered the risk related to retrospective design as intermediate, because the outcomes assessment was retrospective and the generation of hypothesis was prospective. Fourth, risk of bias related to groups' comparability was 
Table 1 Characteristics of included studies

\begin{tabular}{|c|c|c|c|c|c|c|c|c|c|}
\hline \multirow{2}{*}{$\begin{array}{l}\text { Author and } \\
\text { publication year }\end{array}$} & \multirow{2}{*}{$\begin{array}{l}\text { Study } \\
\text { design }\end{array}$} & \multirow{2}{*}{$\begin{array}{l}\text { Sample } \\
\text { size }(n)\end{array}$} & \multirow{2}{*}{$\begin{array}{l}\text { Age } \\
\text { (years) }\end{array}$} & \multirow{2}{*}{$\begin{array}{l}\text { Administration } \\
\text { mode }\end{array}$} & \multirow{2}{*}{$\begin{array}{l}\text { Follow-up } \\
\text { period }\end{array}$} & \multirow{2}{*}{$\begin{array}{l}\text { Ascertainment of } \\
\text { asthma }\end{array}$} & \multicolumn{2}{|r|}{ Outcomes } & \multirow{2}{*}{$\begin{array}{l}\text { Endpoint } \\
\text { measure }\end{array}$} \\
\hline & & & & & & & Specific & Combined & \\
\hline Wells et al., 2012 [22] & $\mathrm{RC}$ & 1,828 & $12-56$ & Single inhaler & *2.1(2.0) years & Asthma treatment & -———- & $\begin{array}{l}\text { 1- Asthma-related hospitalization OR } \\
\text { asthma-related ED visit OR Systemic } \\
\text { Corticosteroid use }\end{array}$ & aHR \\
\hline \multirow[t]{4}{*}{ Jacobs et al., 2012 [23] } & $\mathrm{C}-\mathrm{C}$ & 181 & $4-18$ & Not stated & NA & Clinical diagnosis & 1- ICU admission & -——- & $\mathrm{aOR} \mathrm{OR}$ \\
\hline & & & & & & & 2- Deaths & & \\
\hline & & & & & & & 3-Intubation & & \\
\hline & & & & & & & 4- Positive air pressure use & & \\
\hline \multirow[t]{3}{*}{ Stanford et al., 2012 [24] } & $\mathrm{RC}$ & 10,837 & $65-79$ & Single inhaler & 12 months & Claims for asthma & $\begin{array}{l}\text { 1- Asthma-related } \\
\text { hospitalization }\end{array}$ & $\begin{array}{l}\text { 1- Asthma-related hospitalization OR } \\
\text { asthma-related ED visits }\end{array}$ & $\mathrm{aHR}$ \\
\hline & & & & & & & 2- Asthma-related ED visits & & \\
\hline & & & & & & & $\begin{array}{l}\text { 3- Systemic Corticosteroid } \\
\text { use }\end{array}$ & & \\
\hline Guo et al., 2011 [21] & $\mathrm{RC}$ & 514,216 & $0-40$ & $\begin{array}{l}\text { Single \& Separate } \\
\text { inhalers }\end{array}$ & - & Claims for asthma & -——- & $\begin{array}{l}\text { 1- Asthma-related hospitalization OR } \\
\text { asthma-related ED visits OR Asthma-related } \\
\text { intubations }\end{array}$ & $\mathrm{aHR}$ \\
\hline \multirow[t]{2}{*}{ Stanford et al., 2010 [25] } & $\mathrm{RC}$ & 50,428 & $>4$ & Single inhaler & $\begin{array}{l}\text { *290.4 (102.8) } \\
\text { days }\end{array}$ & Claims for asthma & $\begin{array}{l}\text { 1- Asthma-related } \\
\text { hospitalization }\end{array}$ & $\begin{array}{l}\text { 1- Asthma-related hospitalization OR } \\
\text { asthma-related ED visits }\end{array}$ & $\mathrm{aHR}$ \\
\hline & & & & & & & 2- Asthma-related ED visits & & \\
\hline \multirow[t]{3}{*}{ Hagiwara et al., 2010 [26] } & $\mathrm{RC}$ & 894 & $12-64$ & Single inhaler & 3-12 months & Claims for asthma & $\begin{array}{l}\text { 1-Asthma-related } \\
\text { hospitalization }\end{array}$ & 1- Hospitalization OR ED visits & $\mathrm{aOR}$ \\
\hline & & & & & & & 2-Asthma-related ED visits & 2- Hospitalization OR ED visits OR & \\
\hline & & & & & & & 3-Use of SABAs & Systemic Corticosteroid use & \\
\hline \multirow[t]{2}{*}{ Delea et al., 2010 [27] } & $\mathrm{RC}$ & 1,744 & $>12$ & Single inhaler & 3-12 months & Claims for asthma & 1- ED visits & 1- ED visits OR Hospitalization & $\mathrm{aOR}$ \\
\hline & & & & & & & & $\begin{array}{l}\text { 2- ED visits OR hospitalization OR } \\
\text { Systemic Corticosteroid use }\end{array}$ & \\
\hline \multirow[t]{4}{*}{ de Vries et al., 2010 [28] } & $\mathrm{RC}$ & 467,639 & $>18$ & Not stated & 5 years & Claims for asthma & 1- All mortality; & -二-— & aRR \\
\hline & & & & & & & 2- Asthma-related mortality & & \\
\hline & & & & & & & $\begin{array}{l}\text { 3-Asthma-related } \\
\text { hospitalization }\end{array}$ & & \\
\hline & & & & & & & 4-GP visits for exacerbation & & \\
\hline \multirow[t]{4}{*}{ Lee et al., 2010 [29] } & $\mathrm{RC}$ & 28,074 & $18-56$ & $\begin{array}{l}\text { Single \& Separate } \\
\text { inhalers }\end{array}$ & 12 months & Claims for asthma & $\begin{array}{l}\text { 1- Asthma-related } \\
\text { hospitalization }\end{array}$ & -二-二- & OR \\
\hline & & & & & & & 2-Asthma-related ED visits & & \\
\hline & & & & & & & $\begin{array}{l}\text { 3-Systemic Corticosteroid } \\
\text { use }\end{array}$ & & \\
\hline & & & & & & & 4- SABAs use & & \\
\hline
\end{tabular}


Table 1 Characteristics of included studies (Continued)

\begin{tabular}{|c|c|c|c|c|c|c|c|c|c|}
\hline \multirow[t]{3}{*}{ Thomas et al., 2009 [30] } & \multirow[t]{3}{*}{$\mathrm{RC}$} & \multirow[t]{3}{*}{64,348} & \multirow[t]{3}{*}{$10-58$} & \multirow[t]{3}{*}{$\begin{array}{l}\text { Single \& Separate } \\
\text { inhalers }\end{array}$} & \multirow[t]{3}{*}{12 months } & \multirow{3}{*}{$\begin{array}{l}\text { Claims for asthma } \\
\text { and asthma } \\
\text { treatment }\end{array}$} & $\begin{array}{l}\text { 1- Respiratory } \\
\text { Hospitalization }\end{array}$ & \multirow{3}{*}{$\begin{array}{l}\text { 1- Asthma-related hospitalization OR } \\
\text { asthma-related ED visits OR }>2 \text { prescription } \\
\text { of Systemic Corticosteroid uses OR } \\
\text { SABA prescription }\end{array}$} & \multirow[t]{3}{*}{$\mathrm{aOR}$} \\
\hline & & & & & & & $\begin{array}{l}\text { 2- Systemic Corticosteroid } \\
\text { use }\end{array}$ & & \\
\hline & & & & & & & 3- SABAs use & & \\
\hline \multirow[t]{2}{*}{ Stanford et al., 2008 [31] } & \multirow[t]{2}{*}{$\mathrm{RC}$} & \multirow[t]{2}{*}{58,270} & \multirow[t]{2}{*}{$>12$} & \multirow[t]{2}{*}{ Single inhaler } & \multirow[t]{2}{*}{12 months } & \multirow[t]{2}{*}{ Claim for asthma } & $\begin{array}{l}\text { 1-Asthma-related } \\
\text { Hospitalization }\end{array}$ & \multirow[t]{2}{*}{$\begin{array}{l}\text { 1- Asthma-related ED visits OR } \\
\text { asthma-related Hospitalization }\end{array}$} & $\mathrm{aOR}$ \\
\hline & & & & & & & 2- Asthma-related ED visits & & aHR \\
\hline Campbell et al., 2008 [32] & PC & 684 & $>18$ & Single inhaler & 24 months & Severe asthma & -——— & $\begin{array}{l}\text { 1- Asthma-related hospitalization OR } \\
\text { asthma-related ED visit OR Systemic } \\
\text { Corticosteroid use }\end{array}$ & $\mathrm{aOR} O \mathrm{R}$ \\
\hline \multirow[t]{2}{*}{ Colice et al., 2008 [33] } & \multirow[t]{2}{*}{$\mathrm{RC}$} & \multirow[t]{2}{*}{1,283} & \multirow[t]{2}{*}{$6-64$} & \multirow[t]{2}{*}{ Not stated } & \multirow[t]{2}{*}{12 months } & \multirow[t]{2}{*}{ Claims for asthma } & $\begin{array}{l}\text { 1- Asthma-related } \\
\text { hospitalization }\end{array}$ & -——-— & \multirow[t]{2}{*}{ OR } \\
\hline & & & & & & & 2- Asthma-related ED visits & & \\
\hline \multirow[t]{3}{*}{ Delea et al., 2008 [34] } & \multirow[t]{3}{*}{$\mathrm{RC}$} & \multirow[t]{3}{*}{2,269} & \multirow[t]{3}{*}{$>5$} & \multirow[t]{3}{*}{$\begin{array}{l}\text { Single \& Separate } \\
\text { inhalers }\end{array}$} & \multirow[t]{3}{*}{12 months } & \multirow[t]{3}{*}{ Claims for asthma } & $\begin{array}{l}\text { 1- Asthma-related } \\
\text { hospitalization }\end{array}$ & $\begin{array}{l}\text { 1- Asthma-related hospitalization OR ED } \\
\text { visits OR Systemic Corticosteroid use OR } \\
\text { alternative study medication }\end{array}$ & \multirow[t]{3}{*}{$\mathrm{aOR}$} \\
\hline & & & & & & & 2- Asthma-related ED visits & $\begin{array}{l}\text { 2- Asthma-related hospitalizations OR ED } \\
\text { visits OR oral corticosteroid }\end{array}$ & \\
\hline & & & & & & & 3- Oral corticosteroids use & $\begin{array}{l}\text { 3- Asthma-related hospitalization OR ED } \\
\text { visits hospitalization }\end{array}$ & \\
\hline \multirow[t]{3}{*}{ Friedman et al., 2007 [35] } & $\mathrm{RC}$ & 5,503 & $12-65$ & Single inhaler & 12 months & Claims for asthma & $\begin{array}{l}\text { 1-Asthma-related } \\
\text { hospitalization }\end{array}$ & -ー-ーー & $\mathrm{aOR}$ \\
\hline & & & & & & & 2-Asthma-related ED visits & & \\
\hline & & & & & & & 3- Any ED visits & & \\
\hline Zhang et al., 2007 [36] & $\mathrm{RC}$ & 2,596 & $15-55$ & Single \& Separate & 12 months & Claims for asthma & 1- Oral corticosteroid use & 1- Asthma-related hospitalization OR & OR \\
\hline & & & & & & & 2- SABA use & & \\
\hline Stempel et al., 2006 [37] & $\mathrm{RC}$ & 9,192 & $4-17$ & Single inhaler & 12 months & Claims for asthma & 1- SABA use & 1- Asthma-related hospitalization OR & aRR \\
\hline & & & & & & & 2-Corticosteroids use & & \\
\hline O'Connor et al., 2005 [38] & $\mathrm{RC}$ & 2,414 & $>15$ & $\begin{array}{l}\text { Single \& Separate } \\
\text { inhalers }\end{array}$ & 12 months & Claims for asthma & -——- & $\begin{array}{l}\text { 1- Asthma-related hospitalization OR ED } \\
\text { visits }\end{array}$ & $\mathrm{aOR}$ aHR \\
\hline Nguyen et al., 2005 [20] & B-A & 50 & $4-17$ & Single inhaler & 12 months & Enrolled patients & $\begin{array}{l}\text { 1- Asthma-related } \\
\text { hospitalization }\end{array}$ & -—-—- & $\mathrm{aRR}$ \\
\hline & & & & & & & $\begin{array}{l}\text { 2- Asthma-related ED } \\
\text { visits }\end{array}$ & & \\
\hline
\end{tabular}




\begin{tabular}{|c|c|c|c|c|}
\hline \multirow{3}{*}{$\begin{array}{l}\text { Wells et al. } 2012 \\
\text { Jacobs et al. } 2012\end{array}$} & 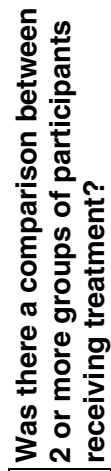 & 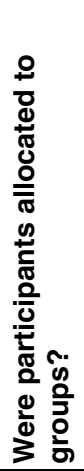 & 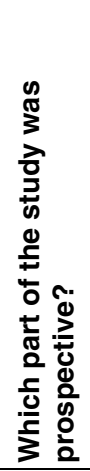 & 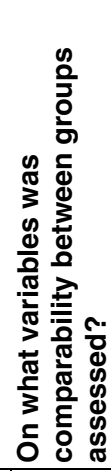 \\
\hline & $\odot$ & $+1-$ & $+/$ & $+1-$ \\
\hline & $\odot$ & $+1-$ & $+/-$ & $\odot$ \\
\hline Stanford et al. 2012 & $\odot$ & $+1-$ & $+/-$ & $\odot$ \\
\hline \multirow{2}{*}{$\begin{array}{l}\text { Guo et al. } 2011 \\
\text { Stanford et al. } 2010\end{array}$} & $\odot$ & $+/-$ & $+/$ & $+/-$ \\
\hline & $\odot$ & $+/$ & $+/$ & $\odot$ \\
\hline Hagiwara et al.2010 & $\odot$ & $+/$ & $+/$ & $\odot$ \\
\hline \multirow{2}{*}{$\begin{array}{l}\text { Delea et al.2010 } \\
\text { de Vries et al.2010 }\end{array}$} & $\odot$ & $+1-$ & $+/$ & $\odot$ \\
\hline & $\odot$ & $+/-$ & $+/$ & $+/$ \\
\hline Lee et al.2010 & $\odot$ & $+/$ & $+/$ & $+1-$ \\
\hline \multirow[t]{2}{*}{ Thomas et al.2009 } & $\odot$ & $+/-$ & $+/$ & $\odot$ \\
\hline & $\odot$ & $+1-$ & $+/-$ & $\odot$ \\
\hline Campbell et al. 2008 & $\odot$ & $+1-$ & $+/$ & $\odot$ \\
\hline \multirow[t]{2}{*}{ Colice et al. 2008} & $\odot$ & $+1-$ & $+/$ & $\odot$ \\
\hline & $\odot$ & $+/-$ & $+/$ & $\odot$ \\
\hline \multirow[t]{2}{*}{ Friedman et al.2007 } & $\odot$ & $+1-$ & $+1-$ & $+1-$ \\
\hline & $\odot$ & $+/$ & $+/$ & $+1-$ \\
\hline \multirow[t]{2}{*}{ Stempel et al.2006 } & $\odot$ & $+1-$ & $+/-$ & $\odot$ \\
\hline & $\odot$ & $+/-$ & $+/$ & $\odot$ \\
\hline Nguyen et al.2005 & $\odot$ & $+1-$ & $+/$ & $\odot$ \\
\hline
\end{tabular}

Figure 2 Risk of bias assessment in individual studies.

not identified in most cases because ORs were adjusted for potential confounders and studies compared outcome variables at baseline. Only the study of Colice et al. [33] had not done either of these two procedures (red mark on Figure 2).

\section{Meta-analyses results}

Of the 19 studies identified, 6 were not included in the meta-analyses performed (4 retrospective cohorts, the case-control, and the before-after study) because they did not provide any of the specific estimators assessed.
The most commonly reported outcomes were emergency department (ED) visit and asthma-related hospitalization (reported in 9 and 8 studies, respectively), followed by systemic corticosteroid use (4 studies). There were also two commonly combined outcomes: asthma-related hospitalizations, asthma-related ED visits or systemic corticosteroid (5 studies); and asthma-related hospitalizations or asthma-related ED visits (9 studies). The latter metaanalysis was not reported because it presented considerable heterogeneity $\left(I^{2}=93 \%\right)$.

Subgroup analyses concerning age and administration mode (single or separate inhalers) could not be performed due to the lack of studies providing disaggregated information for these groups. The three studies focused on children and adolescents had different designs (case-control, before-after and retrospective), and only two of the four retrospective cohorts which included adults and children stratified their analysis by age subgroups. Regarding administration mode, 10 studies included only users of fixed-dose LABAs plus ICs in a single inhaler, three studies did not provide this information, and only three of the six studies which included LABAs plus ICs both as single or two separate inhalers performed disaggregate analysis (Guo et al. [21], Delea et al. [34], and O'Connor et al. [38]).

\section{Asthma-related hospitalizations}

Figure 3 shows the Forest plot (Figure 3a), Galbraith plot (Figure 3b), and Funnel plot (Figure 3c) of the asthmarelated hospitalization meta-analysis. Estimators of this outcome were provided by 8 of the retrospective cohorts. Overall, these studies included 624,303 patients. Results from the study by Delea et al. [34] were included as 2 different estimators because specific ORs for single and separate inhalers (instead of an overall OR) were provided. The ORs of the individual studies ranged from 0.72 (95\% CI 0.55-0.95) reported by Stanford et al. [24] to 4.52 (95\% CI 0.28-72.53) reported by Delea et al. [34]. The summary OR was 0.88 (95\% CI 0.69-1.12). Random effect models were used due to substantial heterogeneity $\left(\mathrm{I}^{2}=66 \%\right)$. The Galbraith plot (Figure $3 \mathrm{~b}$ ) showed that all points except the study corresponding to deVries et al. [28] fell within the confidence limits. However, this has a considerable weight due to the large sample size $(\mathrm{n}=467,639)$. The Funnel plot (Figure 3c) seems symmetric and Egger's test was non-significant, which suggests that there was no publication bias.

\section{Asthma-related ED visits}

The forest plot of the risk of asthma-related ED visits was constructed from 9 studies including 153,799 patients (Figure 4). All the ORs of the individual studies were lower than 1 and the overall summary OR was 0.75 (95\% CI 0.66-0.84). A fixed effect model was used 

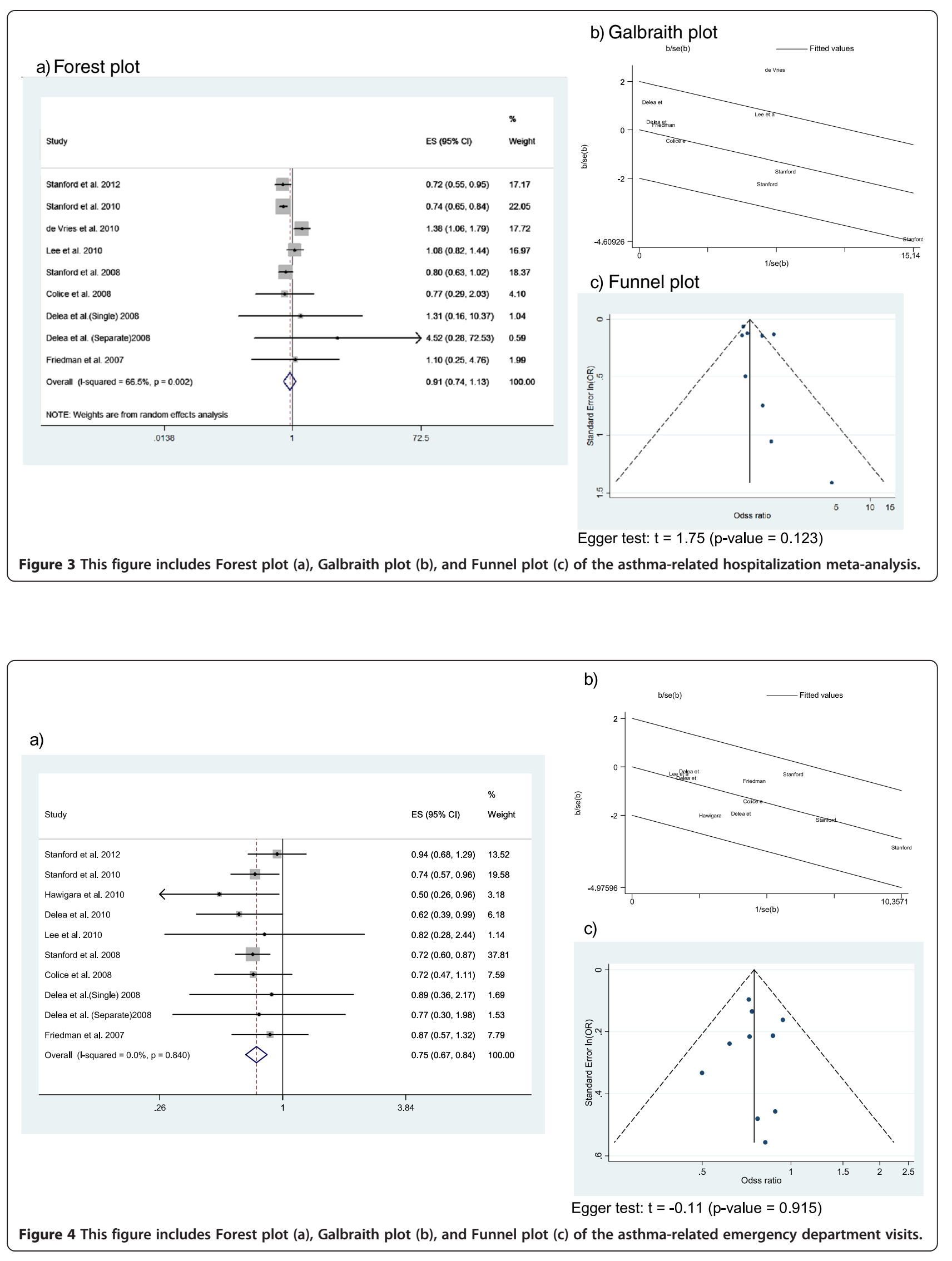
because there was no heterogeneity. Galbraith plot showed that most studies fell within the confidence limits, and the Funnel plot suggested no publication bias.

\section{Asthma-related systemic corticosteroid use}

Four studies (105,855 patients in total) provided estimators of asthma-related systemic corticosteroid use risk (Figure 5). Results from the study by Thomas et al. [30] were included as four separate estimators because ORs were provided for each age group. The summary OR was 1.02 (95\% CI 0.94-1.10), calculated with a fixed effects model as no heterogeneity was found. All studies fell inside the confidence limits of Galbraith plot, and the funnel plot appeared symmetric.

\section{Combined outcome of asthma-related hospitalizations, asthma-related ED visits or systemic corticosteroid use}

Data from 5 studies were available for severe asthma exacerbations meta-analysis (Figure 6), defined as asthma-related hospitalizations, asthma-related ED visits or systemic corticosteroid use. Overall, these studies included 69,939 patients and the summary OR was 0.95 (95\% CI 0.9-1). Results from the study by Campbell et al. [32] were included as two separate estimators because ORs were provided for both low and high corticosteroid doses. The latter is the only individual estimator above $1(\mathrm{OR}=1.42 ; 95 \%$ CI 0.92-2.19). A random effects model was used, as substantial heterogeneity was found $\left(\mathrm{I}^{2}=70 \%\right)$. Figure $6 \mathrm{~b}$ shows that estimators provided by Campbell et al. [32], Hagiwara et al. [26], and Delea et al. [34] fell just outside the confidence limits. Similarly, three estimators are placed outside the triangle in the funnel plot. As there are only 5 studies included in this meta-analyses, Egger's test cannot be interpreted.

\section{Discussion}

To date, less than $10 \%$ of all systematic reviews have adverse events' assessment as a primary objective [39]. Our findings support the relevance and suitability of performing systematic reviews of harms to provide valuable information on these risks. This systematic review identified 19 studies which met the inclusion criteria: 16 retrospective cohorts, 1 prospective cohort, 1 case-control, and 1 before-after study $(1,165,342$ participants). The metaanalyses performed (69,939-624,303 participants according to the outcome considered) showed that the LABAs/ ICs combined treatment was not associated to a higher risk of adverse events, when compared with ICs alone. The OR ranged from 0.75 to 1.02 for the different outcomes explored, which is congruent with findings from meta-analyses of RCTs assessing asthma-related serious

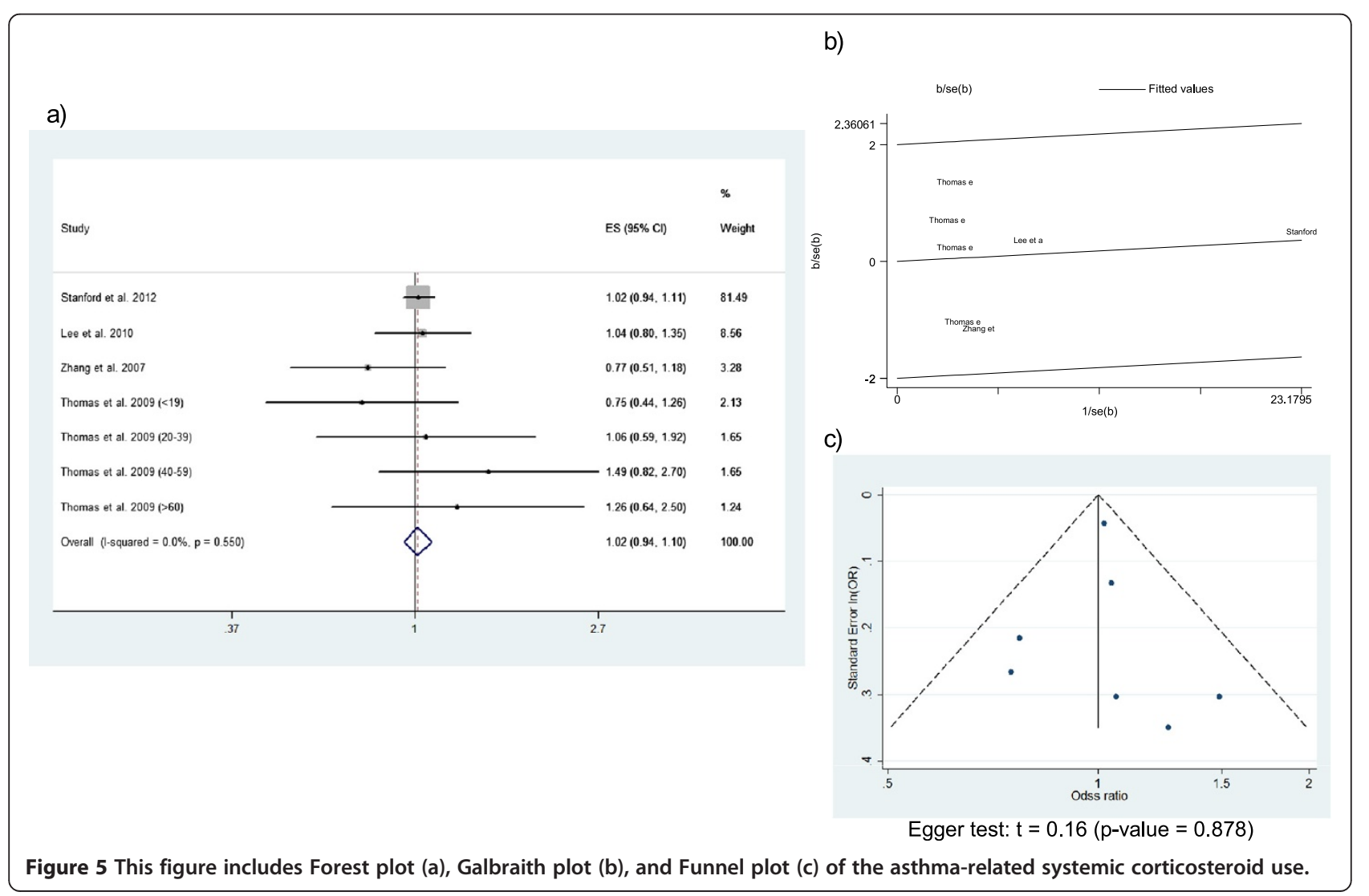




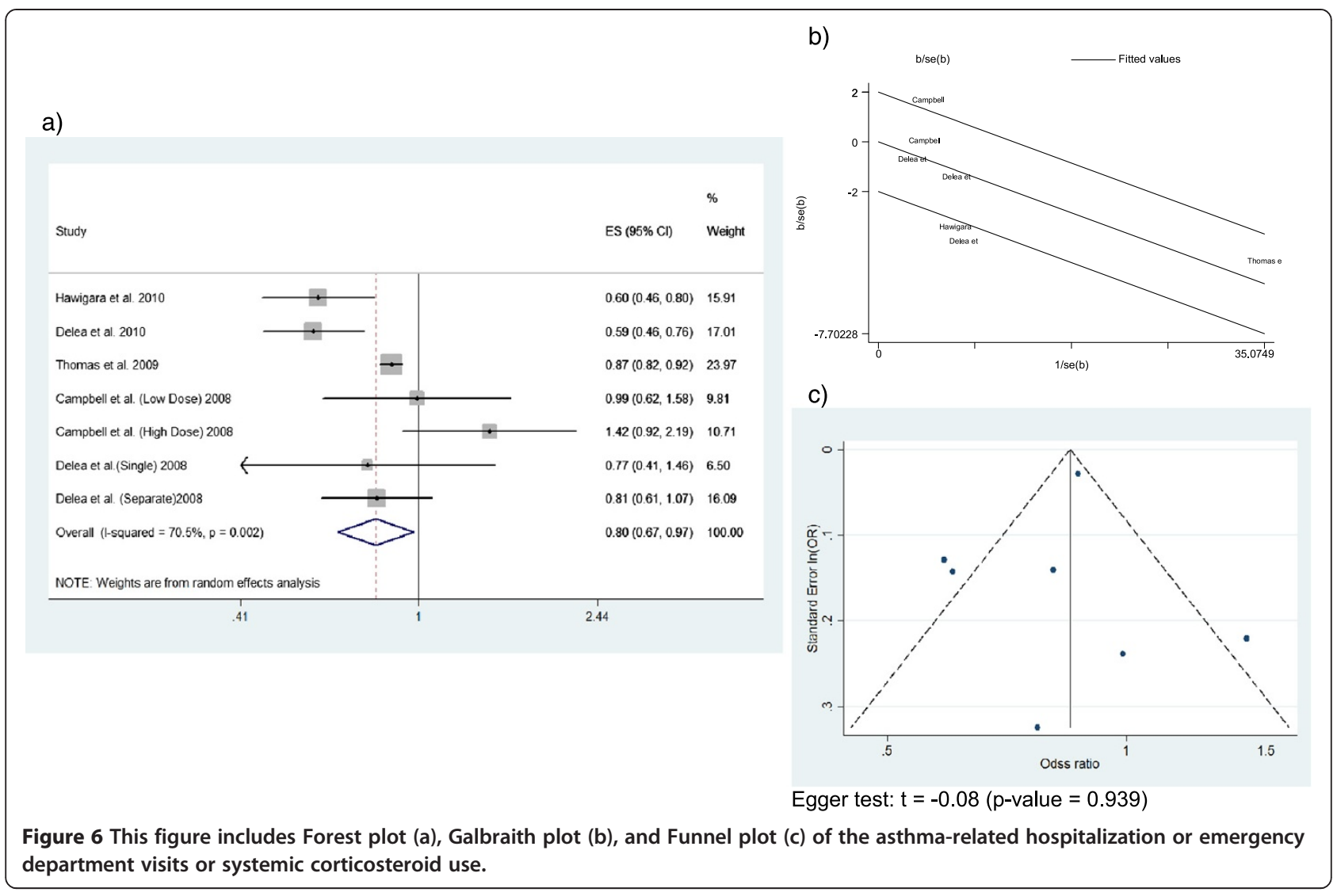

adverse events for salmeterol (0.95; 95\% CI 0.52-1.73) [8] and formoterol $(0.53$; 95\% CI 0.28-1.0) [10].

This consistency between our results and those from meta-analyses of RCTs reinforces the evidence available on this topic. It is well known that RCTs are the gold standard in evaluating efficacy and safety of emerging therapies. However, their poor external validity [40] is a particular concern for long term chronic conditions that affect large and heterogeneous patient populations, such as asthmatics. In fact, it has been estimated that only $1.2 \%$ [41] or 5\% [42] of the usual care asthma population could have been eligible for a typical asthma RCT. In this context, despite potential issues regarding observational studies' internal validity, they are gaining widespread recognition $[43,44]$ providing valuable information on treatment effectiveness and safety, especially in long-term outcomes.

To our knowledge, this is the first systematic review of non-randomized studies including children and adults with asthma to assess adverse events of LABAs, as the only systematic review of observational studies previously published was limited to adult patients (asthma-related hospitalizations $\mathrm{OR}=0.85$; 96\%CI 0.74-0.97) [17]. It included mainly unpublished studies identified from a pharmaceutical company's research register. Since then, the publication of 12 observational studies permitted the inclusion of a larger number of patients. In comparison with systematic reviews of salmeterol and formoterol RCTs (with 15,309 and 13,366 patients, respectively), synthesis of non-randomized studies provides results from larger representative asthma samples, more accurate reflection of the usual clinical practice, and longer followup periods. The follow-up periods of studies included in our systematic review ranged from 3 months to 5 years, being in most cases 1 year (12 studies), an adequate frame of time for the assessment of adverse events [19].

We identified several limitations on our review process. First, four retrospective cohorts could not be included in any of the meta-analyses performed due mainly to the lack of the specific estimator needed, but their results were consistent with our findings [21,22,37,38]. Second, outcomes of these retrospective cohorts varied substantially, from systemic corticosteroids use to deaths. Related to this wide range of clinical outcomes, there was a limitation for synthesizing them by meta-analysis - mortality, a primary outcome of interest, was reported only by one study [28]. Furthermore, the use of composite endpoints could give misleading conclusions because the components have different relevance [45]. However, not only the composite endpoints, but also the individual adverse events which compose them have been considered in the meta-analyses. Third, internal validity of the summary provided by a 
meta-analysis depends on the quality of primary studies. Confounding and selection bias could distort the findings from observational studies and therefore meta-analyses including them would produce biased estimates also. In our systematic review, sensitivity analysis by quality assessment was not performed as risk of bias was homogeneous among studies. Quality assessment was considered moderate for most of them because the studies were mainly comparative, allocation was based on treatment decisions, and adjusted by potential confounders. In fact, only few unadjusted estimators were included in the meta-analysis, and the sensitivity analyses carried out to assess the impact of excluding them, showed similar summary ORs: 0.89 (95\% CI 0.69-1.15) for asthma-related hospitalization and 0.75 (95\% CI 0.67-0.85) for asthma-related ED visits.

Most of the retrospective cohort studies identified in this systematic review obtained data from administrative medical claims and electronic health records, with definitions based on medication prescriptions and ICD-9 diagnosis (i.e. asthma codes for inclusion and other respiratory conditions for exclusion). The main limitations derived from designs of this nature include: a) presence of a prescription claim does not necessarily indicate that the medication was taken; and b) asthma severity criteria were not applied in most studies, and in those that did, severity definitions were based on medication use instead of spirometry or clinical parameters. To balance treatment groups, most of the studies made adjustments on baseline risk factors and socioeconomic variables by using regression models and propensity score matching. Nevertheless, possible confounding factors such as severity and adherence could still remain.

The planned subgroup analysis for children and administration mode (as single or two separate inhalers) could not be conducted, and merits further comments. Stanford et al. [25] performed an analysis stratified by age groups with similar results for adults and children aged 4-18 years: OR was 0.917 (95\% CI 0.85-0.98) for ED visit and 0.88 (95\% CI 0.7-1.11) for hospitalization. The case-control study by Jacobs et al. [23] showed that paediatric LABA use in combination with ICs did not increase the likelihood of intensive care unit admission among hospitalized children, compared to ICs alone. Regarding administration mode, the little available evidence is controversial. The largest retrospective cohort identified in this review [21] is remarkable because it showed higher risk for single inhalers compared with separate inhalers on a combined outcome composed of asthmarelated hospitalizations, intubations or asthma-related ED visits: OR of 1.13 (95\% CI 1.09-1.16) among newly diagnosed patients, and OR of 1.12 (95\% CI 1.10-1.12) among those with pre-existing asthma. On the contrary, in the study by O'Connor et al. [38] patients receiving LABAs plus ICs in a single inhaler were less likely to have an ED visit or to be hospitalized, compared with patients receiving the same treatment in separate inhalers (OR 0.69, 95\% CI 0.51-.95). Delea et al. [34] showed similar results in both administration modes.

Heterogeneity was substantial $(66.5 \%$ and $70.5 \%)$ in two of the four meta-analyses reported. In those conducted with asthma-related hospitalization risk, the only study out of the confidence limits in the Galbraith plot was deVries et al. [28]. This study differs from the other ones in having a follow-up period of 5 years, but many other possible reasons could explain such heterogeneity. In the metaanalysis conducted with the combined outcome, the only estimator that fell outside the Galbraith plot limits was the group with high dose of corticosteroids and salmeterol in Campbell et al. [32], with an OR higher than 1. This might reflect that despite the adjustments, patients taking high corticosteroid doses represented a more severe group.

Almost two thirds of the studies were performed by Glaxo Smith Kline Beecham, while others received industry support without describing the extent of involvement of their sponsors. Usually, publication bias refers to the journals' rejection of studies with negative results. Yet safety studies sponsored by the pharmaceutical industry could suffer from publication bias in the opposite direction, as it is more likely to publish negative results and to select the most favourable outcomes. We have found no evidence of publication bias in the metaanalyses reported, but Egger's test has limited power when the number of studies is low, and funnel plots may have subjective interpretation.

\section{Conclusions}

The current evidence from non-randomized studies shows that combined treatment of LABAs and ICs is not associated with higher risk of serious adverse events. Our systematic review identified major gaps in the available literature; accordingly our key recommendations for further research are to conduct prospective cohort studies, to perform studies among the paediatric population, and to include mortality as a primary outcome. Accumulative valid data is needed to allow evidence-based decisions taking into account safety of LABAs plus ICs in asthma treatment.

\section{Additional file}

Additional file 1: The additional file contains the search strategy, the inclusion and exclusion criteria, the risk of bias assessment tool and information regarding the articles excluded at each step of the Systematic Review.

\section{Abbreviations}

ICs: Inhaled corticosteroids; LABAs: Long-acting beta2-agonists; SABAs: Short acting beta agonists; RCT: Randomized clinical trial; FDA: Federal Drug Administration; ED: Emergency department; ICU: Intensive care unit admissions; Cl: Confidence intervals; HR: Hazard ratio. 


\section{Competing interests}

The authors declare that they have no competing interests.

\section{Authors' contributions}

$\mathrm{GH}$ contributed to the conception and design of the article, conceptualized and oversaw analyses, contributed to the interpretation of data, and wrote the article. MA contributed to the reviewing and web search of included and excluded articles. AP contributed to the analysis and gave statistical support. OG, JA, CC, LL oversaw all aspects and reviewed the article for important intellectual content. MF oversaw all aspects, contributed to the conception and design of the article, contributed to the statistical analyses, carried out the interpretation of data, and contributed to the writing of the article. All the co-authors critically revised the manuscript and approved the final draft before submission.

\section{Acknowledgments}

We would like to thank A. Martin (IMIM Hospital del Mar Medical Research Institute) for the English review and editing of the manuscript.

Members of the ASTRO-LAB group are: Marijn De Bruin, Alexandra Dima (ASCoR, University of Amsterdam, The Netherlands); Eric Van Ganse, Laurent Laforest, Sandrine Herbage, Manon Belhassen, Marine Ginoux (LBBE, University Claude Bernard Lyon 1, France); Stéphane Schück, Nathalie Texier, Sandy Leproust, Hélène Le Cloarec (Kappa Santé, France); Richard Hubbard (University of Nottingham, England); Alison Bourke, Mary Thompson, Delphine Vial, David Ansell (Cegedim Strategic Data, England); Javier Olaiz, Ana Valcarcel Orti (Lyon Ingénierie Projet, France) ; and Montse Ferrer, Olatz Garin, Gimena Hernández (IMIM - Hospital del Mar Medical Research Institute, Spain).

\section{Fundings}

Financial support for this study was provided by the Health Research Fund (European Union FP7, ASTROLAB project EC HEALTH-F5-2011-282593); the Agency for Management of University and Research Grants AGAUR (2012FI_B1 00177); and a Fundación Carolina Fellowship. The funding agreement ensures the authors' independence in designing the study, interpreting the data, and writing and publishing the report. None of these organizations had any role in the design or conduction of the study, nor in the data collection, management or interpretation, nor in the manuscript writing, reviewing, or approval.

\section{Author details}

${ }^{1}$ Health Services Research Group. IMIM (Hospital del Mar Medical Research Institute), Barcelona Biomedical Research Park, office 144. Doctor Aiguader, 88 | 08003, Barcelona, Spain. ${ }^{2}$ Universitat Autònoma de Barcelona, Bellaterra, Spain. ${ }^{3}$ CIBER en Epidemiología y Salud Pública, CIBERESP, Madrid, Spain. ${ }^{4}$ Pompeu Fabra University (UPF), Barcelona, Spain. ${ }^{5}$ UCBL Unité de Pharmacoépidémiologie - UMR 5558 CNRS - Université Claude Bernard, Lyon, France. ${ }^{6}$ St George's University of London, Population Health Sciences and Education, London, UK.

Received: 15 April 2014 Accepted: 14 July 2014

Published: 19 July 2014

\section{References}

1. Walters EH, Gibson PG, Lasserson TJ, Walters JA: Long-acting beta2agonists for chronic asthma in adults and children where background therapy contains varied or no inhaled corticosteroid. Cochrane Database Syst Rev 2007, 1:1-340.

2. Castle W, Fuller R, Hall J, Palmer J: Serevent nationwide surveillance study: comparison of salmeterol with salbutamol in asthmatic patients who require regular bronchodilator treatment. BMJ 1993, 306:1034-1037.

3. Levenson M: Long-acting beta-agonists and adverse asthma events meta-analysis: Briefing package for joint meeting of the PulmonaryAllergy Drug Advisory Committee and Pediatric Advisory Committee on December 10-11, 2008. 2012, Available from URL: http://www.fda.gov/ ohrms/dockets/ac/08/briefing/2008-4398b1-01-FDA.pdf [cited 2012 Oct 4].

4. Nelson HS, Weiss ST, Bleecker ER, Yancey SW, Dorinsky PM: The Salmeterol Multicenter Asthma Research Trial: a comparison of usual pharmacotherapy for asthma or usual pharmacotherapy plus salmeterol. Chest 2006, 129:15-26.

5. Cates CJ, Cates MJ: Regular treatment with formoterol for chronic asthma: serious adverse events. Cochrane Database Syst Rev 2012, 4, CD006923.
6. Weatherall M, Wijesinghe M, Perrin K, Harwood M, Beasley R: Meta-analysis of the risk of mortality with salmeterol and the effect of concomitant inhaled corticosteroid therapy. Thorax 2010, 65:39-43.

7. Jaeschke R, O'Byrne PM, Mejza F, Nair P, Lesniak W, Brozek J, Thabane L, Cheng J, Schunemann HJ, Sears MR, Guyatt G: The safety of long-acting beta-agonists among patients with asthma using inhaled corticosteroids: systematic review and metaanalysis. Am J Respir Crit Care Med 2008, 178:1009-1016.

8. Cates CJ, Jaeschke R, Schmidt S, Ferrer M: Regular treatment with salmeterol and inhaled steroids for chronic asthma: serious adverse events. Cochrane Database Syst Rev 2013, 3:1-79.

9. Bateman E, Nelson H, Bousquet J, Kral K, Sutton L, Ortega H, Yancey S: Meta-analysis: effects of adding salmeterol to inhaled corticosteroids on serious asthma-related events. Ann Intern Med 2008, 149:33-42.

10. Cates CJ, Jaeschke R, Schmidt S, Ferrer M: Regular treatment with formoterol and inhaled steroids for chronic asthma: serious adverse events. Cochrane Database Syst Rev 2013, 6:1-82.

11. Salpeter SR: An update on the safety of long-acting beta-agonists in asthma patients using inhaled corticosteroids. Expert Opin Drug Saf 2010, 9:407-419.

12. Lipworth BJ: Long-acting beta2-adrenoceptor agonists: a smart choice for asthma? Trends Pharmacol Sci 2007, 28:257-262.

13. Chowdhury BA, Dal PG: The FDA and safe use of long-acting betaagonists in the treatment of asthma. N Engl J Med 2010, 362:1169-1171.

14. Sears MR: Safety of long-acting beta-agonists: are new data really required? Chest 2009, 136:604-607.

15. Beasley $\mathrm{R}$, Perrin $\mathrm{K}$, Weatherall $\mathrm{M}$, Wijesinghe $\mathrm{M}$ : Call for withdrawal of LABA single-therapy inhaler in asthma. Lancet 2010, 376:750-751.

16. Wijesinghe M, Perrin K, Harwood M, Weatherall M, Beasley R: The risk of asthma mortality with inhaled long acting beta-agonists. Postgrad Med J 2008, 84:467-472.

17. Hirst C, Calingaert B, Stanford R, Castellsague J: Use of long-acting betaagonists and inhaled steroids in asthma: meta-analysis of observational studies. J Asthma 2010, 47:439-446.

18. Reddel HK, Taylor DR, Bateman ED, Boulet LP, Boushey HA, Busse WW, Casale TB, Chanez P, Enright PL, Gibson PG, de Jongste JC, Kerstjens HA, Lazarus SC, Levy ML, O'Byrne PM, Partridge MR, Pavord ID, Sears MR, Sterk PJ, Stoloff SW, Sullivan SD, Szefler SJ, Thomas MD, Wenzel SE: An official American Thoracic Society/European Respiratory Society statement: asthma control and exacerbations: standardizing endpoints for clinical asthma trials and clinical practice. Am J Respir Crit Care Med 2009, 180:59-99.

19. Cochrane Group: Cochrane handbook for systematic reviews of interventions-Version 5.1. 2012, Available from URL: http://www.cochranehandbook.org/. [Cited 2012, October 11].

20. Nguyen WT, Stewart C, Fisher K, Tolley E, Lew DB, Self TH: Maintenance asthma treatment with fluticasone/salmeterol combination via Diskus: effect on outcomes in inner-city children enrolled in TennCare. Allergy Asthma Proc 2005, 26:129-134.

21. Guo JJ, Tsai K, Kelton CM, Bian B, Wigle PR: Risk of serious asthma exacerbations associated with long-acting beta agonists among patients with asthma: a retrospective cohort study. Ann Allergy Asthma Immunol 2011, 106:214-222.

22. Wells KE, Peterson EL, Ahmedani BK, Severson RK, Gleason-Comstock J, Williams LK: The relationship between combination inhaled corticosteroid and long-acting beta-agonist use and severe asthma exacerbations in a diverse population. J Allergy Clin Immunol 2012, 129:1274-1279.

23. Jacobs TS, Jones BL, MacGinnitie AJ: Long-acting beta-agonists and the risk of intensive care unit admission in children. J Asthma 2012, 49:450-455.

24. Stanford RH, Blanchette CM, Roberts MH, Petersen H, Fuhlbrigge AL: Effect of combination fluticasone propionate and salmeterol or inhaled corticosteroids on asthma-related outcomes in a Medicare-eligible population. Am J Geriatr Pharmacother 2012, 10:343-351.

25. Stanford RH, Riedel AA, Johnson JC, Astry CL: Comparative resource utilization in medicaid-eligible patients with asthma treated with fixeddose fluticasone propionate/salmeterol or fluticasone propionate monotherapy. Clin Ther 2010, 32:1782-1793.

26. Hagiwara M, Delea TE, Stanford RH, Stempel DA: Stepping down to fluticasone propionate or a lower dose of fluticasone propionate/ salmeterol combination in asthma patients recently initiating combination therapy. Allergy Asthma Proc 2010, 31:203-210.

27. Delea TE, Hagiwara M, Stempel DA, Stanford RH: Adding salmeterol to fluticasone propionate or increasing the dose of fluticasone propionate in patients with asthma. Allergy Asthma Proc 2010, 31:211-218. 
28. De VF, Setakis E, Zhang B, van Staa TP: Long-acting \{beta\}2-agonists in adult asthma and the pattern of risk of death and severe asthma outcomes: a study using the GPRD. Eur Respir J 2010, 36:494-502.

29. Lee TA, Chang CL, Stephenson JJ, Sajjan SG, Maiese EM, Everett S, Allen-Ramey F: Impact of asthma controller medications on medical and economic resource utilization in adult asthma patients. Curr Med Res Opin 2010, 26:2851-2860.

30. Thomas M, Von ZJ, Lee AJ, Price D: High-dose inhaled corticosteroids versus add-on long-acting beta-agonists in asthma: an observational study. J Allergy Clin Immunol 2009, 123:116-121.

31. Stanford RH, Fuhlbrigge A, Riedel A, Rey GG, Stempel DA: An observational study of fixed dose combination fluticasone propionate/salmeterol or fluticasone propionate alone on asthma-related outcomes. Curr Med Res Opin 2008, 24:3141-3148.

32. Campbell JD, Borish L, Haselkorn T, Rasouliyan L, Lee JH, Wenzel SE, Sullivan SD: The response to combination therapy treatment regimens in severe/ difficult-to-treat asthma. Eur Respir J 2008, 32:1237-1242.

33. Colice GL, Yu AP, Ivanova Jl, Hsieh M, Birnbaum HG, Lage MJ, Brewster C: Costs and resource use of mild persistent asthma patients initiated on controller therapy. J Asthma 2008, 45:293-299.

34. Delea TE, Hagiwara M, Stanford RH, Stempel DA: Effects of fluticasone propionate/salmeterol combination on asthma-related health care resource utilization and costs and adherence in children and adults with asthma. Clin Ther 2008, 30:560-571.

35. Friedman HS, Yawn BP: Resource utilization in asthma: combined fluticasone propionate/salmeterol compared with inhaled corticosteroids. Curr Med Res Opin 2007, 23:427-434.

36. Zhang Q, Thomas M, Wisniewski T, Sazonov KV, Price D: Treatment and outcomes in patients with asthma and allergic rhinitis in the United kingdom. Int Arch Allergy Immunol 2007, 142:318-328.

37. Stempel DA, Riedel AA, Carranza Rosenzweig JR: Resource utilization with fluticasone propionate and salmeterol in a single inhaler compared with other controller therapies in children with asthma. Curr Med Res Opin 2006, 22:463-470.

38. O'Connor RD, Rosenzweig JR, Stanford RH, Gilmore AS, Ryskina KL, Legorreta AP, Stempel DA: Asthma-related exacerbations, therapy switching, and therapy discontinuation: a comparison of 3 commonly used controller regimens. Ann Allergy Asthma Immunol 2005, 95:535-540.

39. Zorzela L, Golder S, Liu Y, Pilkington K, Hartling L, Joffe A, Loke Y, Vohra S: Quality of reporting in systematic reviews of adverse events: systematic review. BMJ 2014, 348:77668.

40. Rothwell PM: External validity of randomised controlled trials: "to whom do the results of this trial apply?". Lancet 2005, 365:82-93.

41. Herland K, Akselsen JP, Skjonsberg OH, Bjermer L: How representative are clinical study patients with asthma or COPD for a larger "real life" population of patients with obstructive lung disease? Respir Med 2005, 99:11-19.

42. Travers J, Marsh S, Williams M, Weatherall M, Caldwell B, Shirtcliffe P, Aldington $S$, Beasley R: External validity of randomised controlled trials in asthma: to whom do the results of the trials apply? Thorax 2007, 62:219-223.

43. Concato J, Shah N, Horwitz Rl: Randomized, controlled trials, observational studies, and the hierarchy of research designs. $N$ Engl 」 Med 2000, 342:1887-1892.

44. Hernan MA, Alonso A, Logan R, Grodstein F, Michels KB, Willett WC, Manson $J E$, Robins JM: Observational studies analyzed like randomized experiments: an application to postmenopausal hormone therapy and coronary heart disease. Epidemiology 2008, 19:766-779.

45. Ferreira-Gonzalez I, Busse JW, Heels-Ansdell D, Montori VM, Akl EA, Bryant DM, Alonso-Coello P, Alonso J, Worster A, Upadhye S, Jaeschke R, Schunemann HJ, Permanyer-Miralda G, Pacheco-Huergo V, Domingo-Salvany A, Wu P, Mills EJ, Guyatt GH: Problems with use of composite end points in cardiovascular trials: systematic review of randomised controlled trials. BMJ 2007, 334:786.

doi:10.1186/1465-9921-15-83

Cite this article as: Hernández et al.: Long-acting beta-agonists plus inhaled corticosteroids safety: a systematic review and meta-analysis of non-randomized studies. Respiratory Research 2014 15:83.

\section{Submit your next manuscript to BioMed Central and take full advantage of:}

- Convenient online submission

- Thorough peer review

- No space constraints or color figure charges

- Immediate publication on acceptance

- Inclusion in PubMed, CAS, Scopus and Google Scholar

- Research which is freely available for redistribution

Submit your manuscript at www.biomedcentral.com/submit
() Biomed Central 